\title{
Computational Study of the Stability of Tautomers and equilibrium constants of Cyanuric acid (CA) in Different solvents.
}

\section{Numbury Surendra Babu* and \#Didugu Jayaprakash}

*Department of Chemistry, Hawassa University, Hawassa, Post Box No: 5, Ethiopia.

\section{Email:nsbabusk@gmail.com}

\author{
\#Department of Chemistry, Acharya Nagarjuna University, Nagarjunanagar, Guntur, A.P, INDIA
}

$$
\text { Email: didugujayaprakash@gmail.com }
$$

\section{ABSTRACT}

In the present investigation, the tautomeric and equilibrium of Cyanuricacid has been studied using Hartree Fock (HF) method in the gas phase and different solvents using the PCM model. The relative energies of these tautomers have been calculated at the HF level of theory using $6-311++G(d, p)$ basis set. Energetics and relative stabilities of the tautomers were compared and analyzed in both the gaseous and different solvents. The results indicate that the keto tautomer (CA1) is the most stable form in the gas phase and other solvents. The order of stability of isomers was found to be CA1 $>$ CA3> $\mathrm{CA} 11>\mathrm{CA} 2>\mathrm{CA} 6>\mathrm{CA} 10>\mathrm{CA} 7>\mathrm{CA} 4>\mathrm{CA} 5>\mathrm{CA} 9>\mathrm{CA} 8$. Having the largest dipole moment the CA8 tautomer is expected to have the strongest interaction with polar solvents.The HF method calculated tautomeric equilibrium constants with respect to the most stable tautomer CA1 of Cyanuric acid both in the gas and in different solvents. The $p K_{T}$ of the equilibrium constants calculated starting from the general outline of interconversion.

Key words: Cyanuric acid; Hartree Fock method; Relative stabilities; Equilibrium constantsand solvent effects.

\section{Council for Innovative Research}

Peer Review Research Publishing System

\section{Journal: Journal of Advances in Chemistry}

Vol. 11, No. 2

editorjaconline@gmail.com 


\section{INTRODUCTION}

Studies of tautomerism phenomena have been valuable in many areas of chemistry as demonstrated by several reviews of experimental and theoretical studies in chemistry and biochemistry ${ }^{[1-5]}$. The experimental studies on tautomerism are still a challenging problem in chemistry and molecular biology. Most tautomers are not observed in the experimental studies because of their low concentration. A detailed analysis of the structure and changes in geometrical and energetic parameters caused by the migration of hydrogen atom would enable us to understand the different properties of tautomers. Knowledge of the relative stabilities of tautomeric forms of heterocycles as well as the conversion from one tautomeric form to another is important from the point of view of structural chemistry.

Cyanuric acid has a diverse role to play in chemistry, particular with regard to commercial or industrial use, for many years. It has featured in products ranging from flame retardants and plant growth feed to a catalyst for NOx removal from exhaust and lavatory cleaning blocks ${ }^{[6]}$.CA1exists in equilibrium with its tautomer CA10 or CA11(Refer the figure1)and has the attributes of high symmetry and planarity, coupled with three hydrogen bond donors and three acceptors. It is a middy acidic compound with $\mathrm{pK}_{\mathrm{a}}$ values of $6.85,10.91$ and $>12^{[7]}$. Cyanuric acid is only slightly water soluble and is thermally unstable. At high temperatures, it decomposes to form toxic cyanic acid ${ }^{[8]}$. Cyanuric acid exists preferentially as the oxo tautomer (CA1) rather than the hydroxy form (CA10 or CA11) ${ }^{[9]}$ (sheme1)Commercial applications of Cyanuric acid include stabilizers of swimming pooldisinfectants, household bleach, industrials cleaners, dishwasher detergents, and generalsanitizers. Cyanuric acid has been found to naturally occur in nature insoil humus ${ }^{[8]}$. Melamine combination with Cyanuric acid or the analogues, including ammeline and ammelide, appear to cause crystallization in renal tubules ${ }^{[10]}$. Most of the infants were asymptomatic, and a few suffered from stoneinduced urinary obstruction resulting in acute renal failure ${ }^{[11]}$

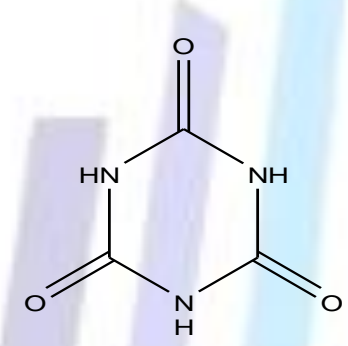

1,3,5-triazinane-2,4,6trione(CA1)

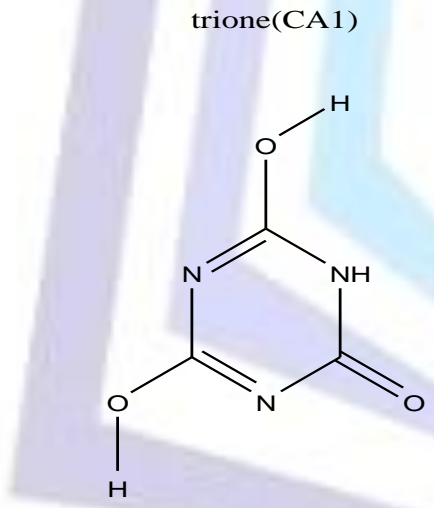

4,6-dihydroxy-1,3,5-triazin 2(1H)-one(CA4)<smiles>[2H]Oc1nc(O[2H])[nH]c(=O)n1</smiles>

4,6-dihydroxy-1,3,5-triazin$2(1 H)$-one $(\mathrm{CA} 7)$

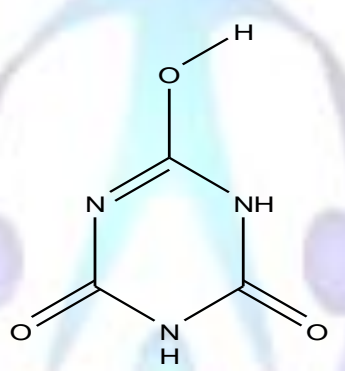

6-hydroxy-1,3,5-triazine-

2,4(1H,3H)-dione(CA2)

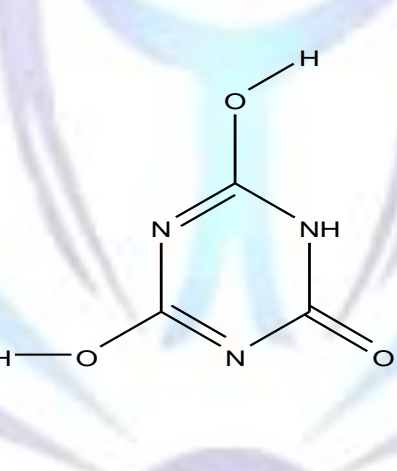

4,6-dihydroxy-1,3,5-triazin2(1H)-one(CA5)<smiles>O=c1nc(O[TlH])[nH]c(O[TlH])n1</smiles>

4,6-dihydroxy-1,3,5-triazin2(5H)-one (CA8)<smiles>O=c1nc(O)[nH]c(=O)[nH]1</smiles>

6-hydroxy-1,3,5-triazine$2,4(1 H, 3 H)$-dione(CA3)

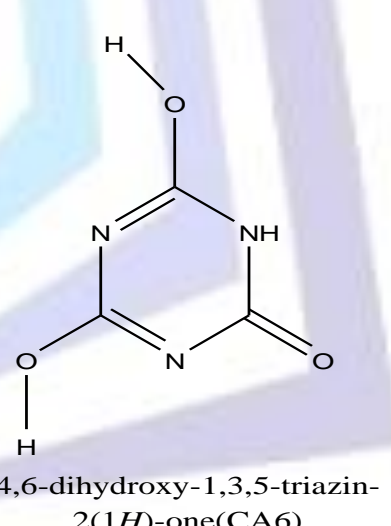
2(1H)-one(CA6) 
<smiles>Oc1nc(O)nc(O)n1</smiles>

1,3,5-triazine-2,4,6-triol(CA10)

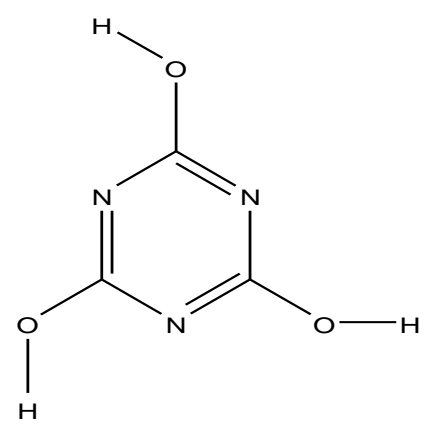

1,3,5-triazine-2,4,6-triol(CA11)

Scheme 1. The selected tautomer structures of cyanuric acid (tautomer CA1(1,3,5-triazinane-2,4,6-trione);CA2 and CA3 (6-hydroxy-1,3,5-triazine-2,4(1H,3H)-dione);CA4,CA5, CA6, and CA7( 4,6-dihydroxy-1,3,5-triazin-2(1H)-one);CA8 and CA9 (4,6-dihydroxy-1,3,5-triazin-2(5H)-one);CA10 and CA11 (1,3,5-triazine-2,4,6-triol).

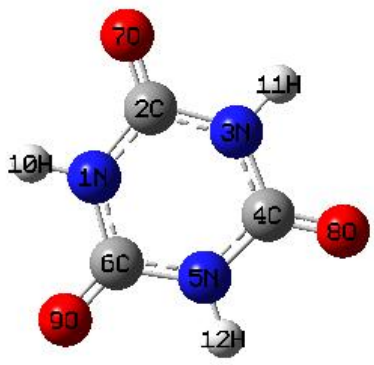

CA1

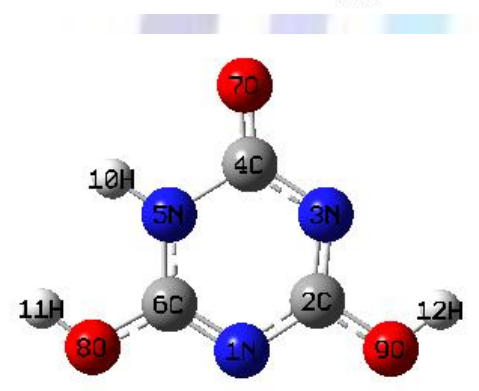

CA4

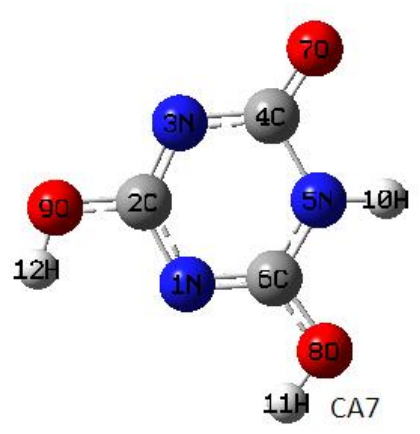

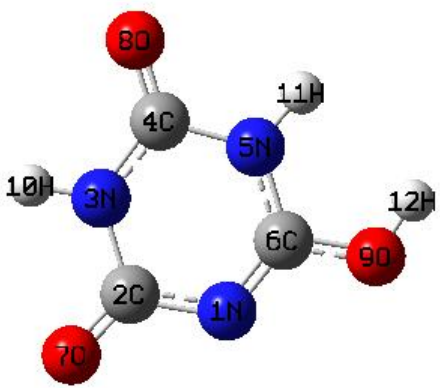

CA2

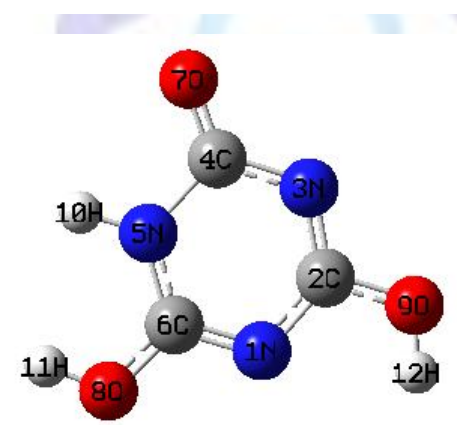

CA4

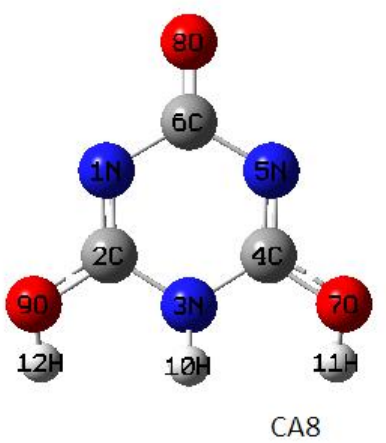

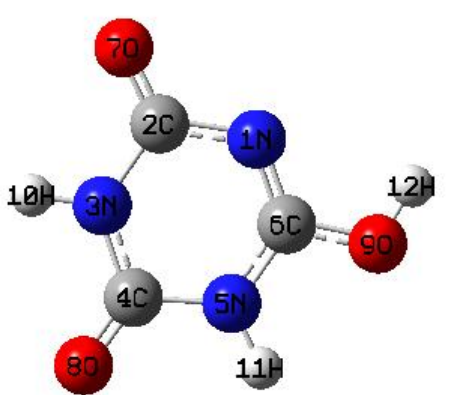

CA3

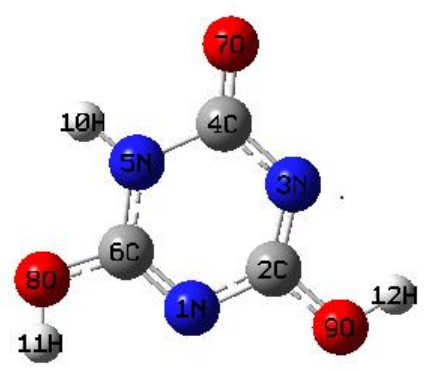

CA6

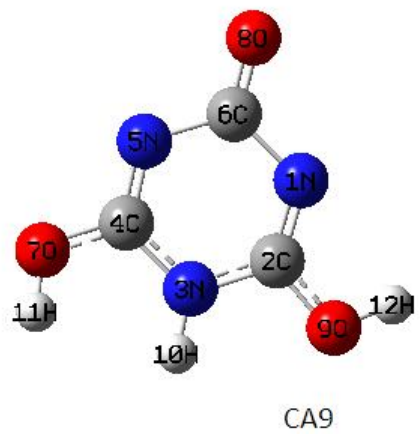




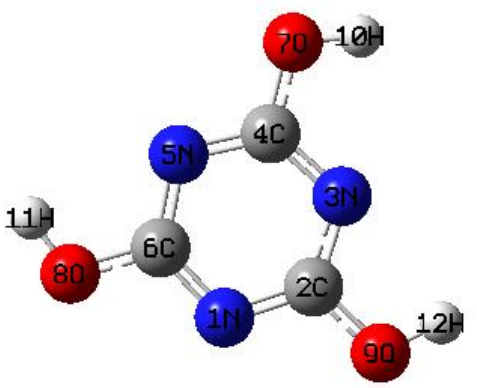

CA10

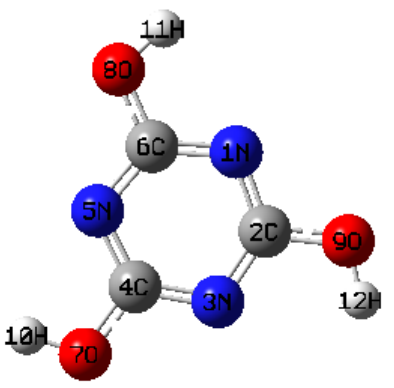

CA11

Figure 1. Leven structural isomers of $\mathrm{C} 3 \mathrm{~N} 3 \mathrm{O} 3 \mathrm{H} 3$ comprising Cyanuric acid (1,3,5-triazinane-2,4,6-trione) (labeled (1)), 6hydroxy-1,3,5-triazine-2,4(1H,3H)- dione ((2) and (3)), 4,6-dihydroxy-1,3,5-triazin-2(1H)-one ((4), (5),(6) (7),(8)and (9)), and 1,3,5-triazine-2,4,6-triol $((10)$ and (11)) in gas phase. Each atom is colored and numbered. Grey is carbon, blue is nitrogen, red is oxygen and white is hydrogen.

In this research article we calculates various parameters to determine, the theoretical possible tautomers of Cyanuric acid. Tautomeric equlibria are important and it is impossible to correctly interpret the detail mechanism of reactions of tautomeric heterocycles without knowing the dominant tautomeric structure. Equally, it is impossible to correctly interpret the biological activity and function of potentially tautomeric heterocycles without representing them in correct structure. Also, understanding of the relative stabilities of heterocyclic tautomers and any subsequent conversions between tautomeric forms is very vital for both structural chemists and biologists ${ }^{[12]}$. Along this line, relative stabilities of various tautomeric structures of five-, six- and seven-membered heterocyclic rings were investigated using both theoretical and experimental tools ${ }^{[13]}$. Tautomerism interconversion has been investigated by chemists during last decades. Recently, study of tautomerism received renewed attention due to its importance on determination of compounds' properties and their area of applications. The importance of tautomerism is revealed more since in recent years the investigation about tautomerism has been the major topic in theoretical chemistry.

\section{COMPUTATIONAL SECTION}

Molecular geometries of tautomeric forms of Cyanuricacid were fully optimized by using the Gaussian quantum chemistry software package Gaussian $09 w^{[14]}$. Programs at the HF level of theory, using the $6-311++G(d, p)$ basis sets ${ }^{[14]}$. Initial geometry generated from standard geometrical parameters minimized without any constraint in the potential energy surface at HF level, adopting the standard $6-311++G(d, p)$ basis set. Following the geometry optimizations, analytical frequency calculations were proceeded at the HF/6-311++G $(d, p)$ level, following standard procedures, to obtain the thermochemical properties. In addition the effects of solvents on the tautomeric structure properties were studied by means of the self-consistent reaction-field (SCRF) method based on PCM developed by Tomasi and coworkers ${ }^{[15]}$. It is one of the most widely used approaches. In this model, a solute is considered inside a cavity and the solvent as a structureless medium characterized by some parameters such as its dielectric constant, molar volume and Polarizability. This consideration can substantially improve the simulation results for the electronic or vibrational spectroscopy of real molecular systems ${ }^{[16,17]}$. The solvents chose for this studies are polar protic solvents namely water $(\varepsilon=74.80)$ andethanol $(\varepsilon=24.55)$ and polar aprotic solvents liketetrahydrofuran(THF) $(\varepsilon=7.50)$ and dimethylformamide $(\varepsilon=38.00)$.

In the present paper, we report the relative stability, Gibbs free energy, enthalpy and entropy, tautomeric equilibrium constants and dipole moments for the Cyanuric acid $298.15 \mathrm{~K}$. After having predicted the relative stability of tautomers, we have found the tautomeric equilibrium constants with respect to the more stabletautomer in the gas phase and indifferent solvents.

\section{RESULTS AND DISCUSSION}

\section{RELATIVE STABILITY}

Cyanuric acid exhibits eleven theoretical possible tautomers and eleven structural isomers of $\mathrm{C}_{3} \mathrm{~N}_{3} \mathrm{O}_{3} \mathrm{H}_{3}$ comprising; Cyanuric acid (1,3,5-triazinane-2,4,6-trione) (labeled (CA1)), 6-hydroxy-1,3,5-triazine-2,4(1H,3H)- dione $((\mathrm{CA} 2)$ and (CA3)), 4,6-dihydroxy-1,3,5-triazin-2(1H)-one ((CA4), (CA5),(CA6) (CA7),(CA8) and (CA9)), and 1,3,5-triazine2,4,6-triol ((CA10) and (CA11)) are in scheme 1. The structures correspond to cyanuric acid species labeled (CA2) and (CA3) are monohydroxytautomers, six are dihydroxytautomers (CA4,CA5,CA6,CA7,CA8 and CA9) and the structures of (CA10 and CA11) aretrihydroxytautomers, these differ in the mono proton,di proton and tri proton transfer and orientation of the hydroxyl group. The optimized geometrics are shown in Figure 2 in gas phase.Each atom is colored and numbered. Grey is carbon, blue is nitrogen, red is oxygen and white is hydrogen. 


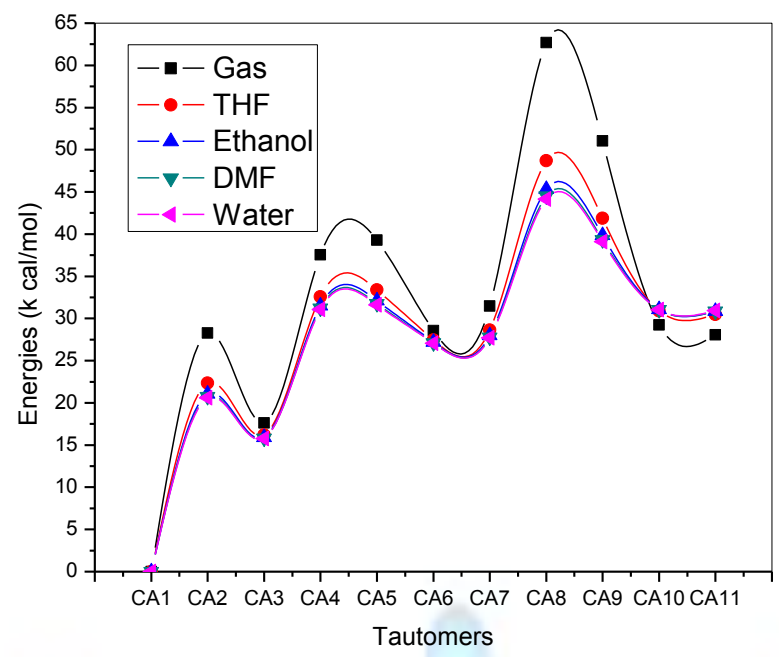

Figure 2. The Relative energies for Tautomers in different solvents

In Tablel, results are presented for the absolute and relative electronic energy in gas and different (aqueous, ethanol, THF and DMF) solution phase, respectively, evaluated at the HF levels of theory in conjunction with $6-311++\mathrm{G}^{* \star}$ basis set. The calculations at the HF levels of theory suggest that the Cyanuric acid form, CA1, is the most stable isomer in both gas phase and different solutions. The order of stability of isomers was found to be CA1 $>C A 3>C A 11>C A 2>$ $\mathrm{CA} 6>\mathrm{CA} 10>\mathrm{CA} 7>\mathrm{CA} 4>\mathrm{CA} 5>\mathrm{CA} 9>\mathrm{CA} 8$. Based on the HF calculations in the gas phase, the energy of CA3,CA11,CA2, CA6, CA10,CA7,CA4,CA5,CA9 and CA8 isomers are 17.62,28.05,28.28,28.55,29.22,31.48,37.27,39.27,51.04 and 62.69 $\mathrm{kcal} / \mathrm{mol}$ higher than CA1 isomer, respectively.Solvent effects are relevant to tautomer stability phenomena, since polarity differences among tautomers can induce significant changes in their relative energies in solutions. For this purpose, the PCM calculations were employed to analyze the solvent effects on tautomerism of Cyanuric acid. The results obtained for different solutions have been reported in Table 1 and compared with those obtained from the gas phase calculations. It is evident that the electronic energies of tautomers decrease in comparison with gas phase. As the dielectric constant of solvent increases the tautomer energy is decreases. The order of stability of tautomers was found in the different solvents to be $\mathrm{CA} 1>\mathrm{CA} 3>\mathrm{CA} 2>\mathrm{CA} 6>\mathrm{CA} 7>\mathrm{CA} 11>\mathrm{CA} 10>\mathrm{CA} 4>\mathrm{CA} 5>\mathrm{CA} 9>\mathrm{CA} 8$ in aqueous phase; CA1 > CA3 > CA2 > $\mathrm{CA} 6>\mathrm{CA} 7>\mathrm{CA} 11>\mathrm{CA} 4>\mathrm{CA} 10>\mathrm{CA} 5>\mathrm{CA} 9>\mathrm{CA} 8$ in ethanol phase; and CA1 > CA3 > CA2 > CA6 > CA7 > CA11 > CA10 > CA4 > CA5 > CA9 > CA8 in both THF and DMF phase. In all phases the tautomer CA1 is morestable.Figure 3 shows the effect of various solvents on the stability of each isomer. The instability of each isomer has been plotted versus its dipole moment which depends on the kind of the selected solvent. It is evident that the CA8 isomer is considerably affected by solvent.

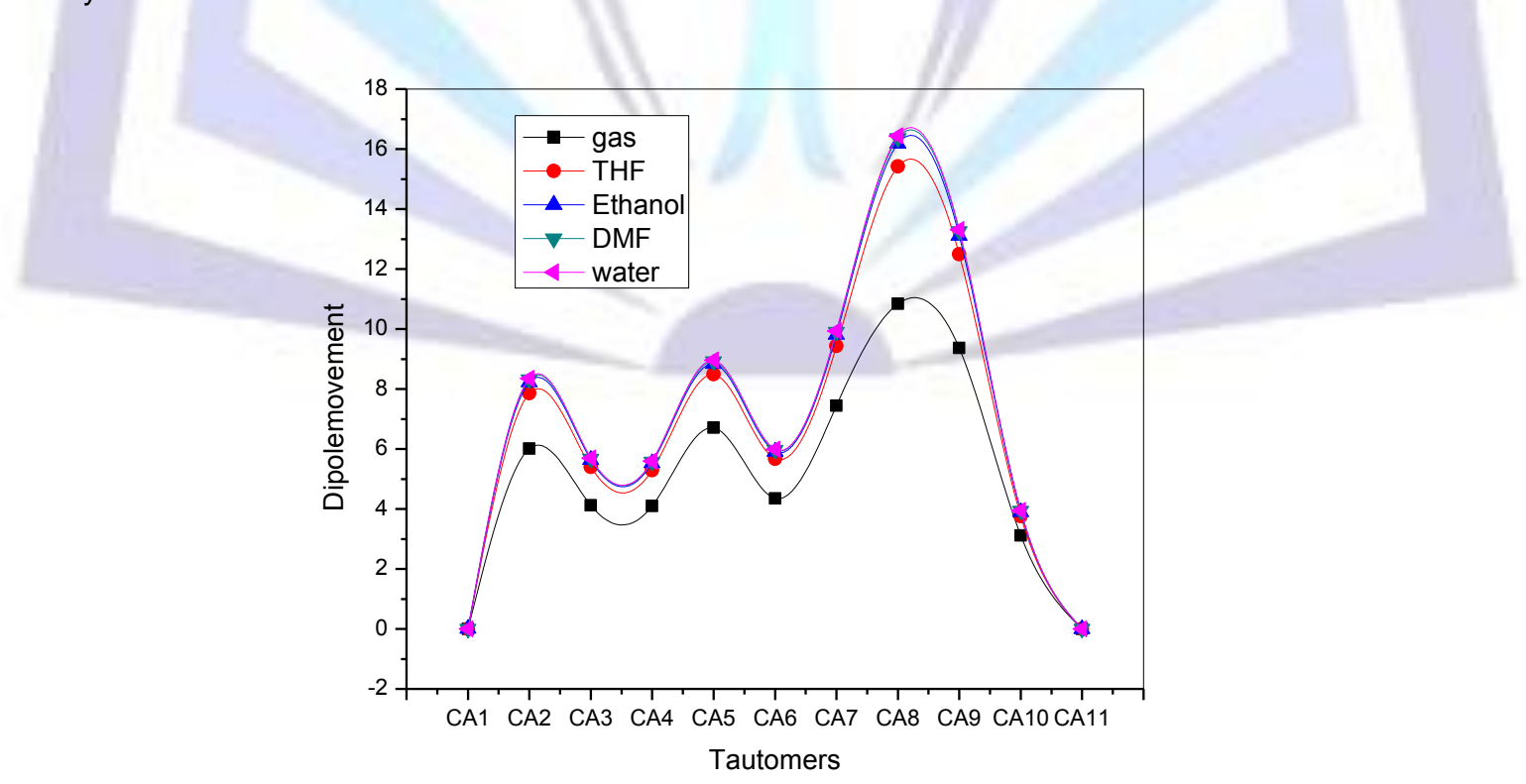

Figure 3. Dipole movements for Tautomers in different solvents 
Table 1. The energies of tautomers(a.u) at HF/6-311++G(d,p) level in different media and the relative energies compared to the most stable isomer CA1. The relative energies in brackets in kcal mol-1.

\begin{tabular}{|c|c|c|c|c|c|}
\hline Tautomer & gas $(\varepsilon=1.00)$ & $\operatorname{THF}(\varepsilon=7.50)$ & ethanol $(\varepsilon=1.00)$ & $\operatorname{DMF}(\varepsilon=24.55)$ & water $(\varepsilon=78.50)$ \\
\hline $\mathrm{CA} 1$ & $-503.5295806(0.00)$ & $\begin{array}{c}-503.5295806 \\
(0.00)\end{array}$ & $\begin{array}{c}-503.549091930 \\
(0.00)\end{array}$ & $-503.549628574(0.00)$ & $\begin{array}{c}-503.549904703 \\
(0.00)\end{array}$ \\
\hline CA2 & $\begin{array}{c}-503.4845165 \\
(28.28)\end{array}$ & $\begin{array}{c}-503.4845165 \\
(22.34)\end{array}$ & $\begin{array}{c}-503.515499106 \\
(21.08)\end{array}$ & $\begin{array}{c}- \\
503.516562962(20.75)\end{array}$ & $\begin{array}{c}-503.517057789 \\
(20.61)\end{array}$ \\
\hline CA3 & $\begin{array}{c}-503.5015004 \\
(17.62)\end{array}$ & $\begin{array}{c}-503.5015004 \\
(16.19)\end{array}$ & $\begin{array}{c}-503.523730220 \\
(15.91)\end{array}$ & $\begin{array}{c}- \\
503.524448503(15.80)\end{array}$ & $\begin{array}{c}-503.524780719 \\
(15.77)\end{array}$ \\
\hline CA4 & $\begin{array}{c}-503.4697602 \\
(37.54)\end{array}$ & $\begin{array}{c}-503.4697602 \\
(32.57)\end{array}$ & $\begin{array}{c}-503.498896899 \\
(31.50)\end{array}$ & $\begin{array}{c}- \\
503.499893327(31.21)\end{array}$ & $\begin{array}{c}-503.500356596 \\
(31.09)\end{array}$ \\
\hline CA5 & $\begin{array}{c}-503.4669966 \\
(39.27)\end{array}$ & $\begin{array}{c}-503.4669966 \\
(33.38)\end{array}$ & $\begin{array}{c}-503.497937766 \\
(32.10)\end{array}$ & $\begin{array}{c}- \\
503.499009109(31.76)\end{array}$ & $\begin{array}{c}-503.499507532 \\
(31.62)\end{array}$ \\
\hline CA6 & $\begin{array}{c}-503.4840763 \\
(28.55)\end{array}$ & $\begin{array}{c}-503.4840763 \\
(27.44)\end{array}$ & $\begin{array}{c}-503.505751459 \\
(27.20)\end{array}$ & $\begin{array}{c}- \\
503.506454752(27.09)\end{array}$ & $\begin{array}{c}-503.506780968 \\
(27.06)\end{array}$ \\
\hline CA7 & $\begin{array}{c}-503.4794190 \\
(31.48)\end{array}$ & $\begin{array}{c}-503.4794190 \\
(28.64)\end{array}$ & $\begin{array}{c}-503.504489135 \\
(27.99)\end{array}$ & $\begin{array}{c}- \\
503.505342321(27.79)\end{array}$ & $\begin{array}{c}-503.505739083 \\
(27.71)\end{array}$ \\
\hline CA8 & $\begin{array}{c}-503.4296812 \\
(62.69)\end{array}$ & $\begin{array}{c}-503.42968120 \\
(48.69)\end{array}$ & $\begin{array}{c}-503.476857997 \\
(45.33)\end{array}$ & $\begin{array}{c}-503.478680666 \\
(44.52)\end{array}$ & $\begin{array}{c}-503.479531705 \\
(44.16)\end{array}$ \\
\hline CA9 & $\begin{array}{c}-503.4482400 \\
(51.04)\end{array}$ & $\begin{array}{c}-503.44824004 \\
(41.89)\end{array}$ & $\begin{array}{c}-503.485600800 \\
(39.84)\end{array}$ & $\begin{array}{c}-503.486951562 \\
(39.33)\end{array}$ & $\begin{array}{c}-503.487581455 \\
(39.11)\end{array}$ \\
\hline CA10 & $\begin{array}{c}-503.4830177 \\
(29.22)\end{array}$ & $\begin{array}{c}-503.4830177 \\
(30.89)\end{array}$ & $\begin{array}{c}-503.499581117 \\
(31.07)\end{array}$ & $503.500143827(31.05)$ & $\begin{array}{c}-503.500405407 \\
(31.06)\end{array}$ \\
\hline CA11 & $\begin{array}{c}- \\
503.4848776(28.05)\end{array}$ & $\begin{array}{c}-503.4848776 \\
(30.47)\end{array}$ & $\begin{array}{c}-503.499877294 \\
(30.88)\end{array}$ & $503.500430658(30.87)$ & $\begin{array}{c}-503.500592144 \\
(30.94)\end{array}$ \\
\hline
\end{tabular}

\section{DIPOLE MOMENT}

As we can see from Table 2, the calculated dipole moments are changed on moving from thegas phase $(\varepsilon=1)$ to solvents $\operatorname{THF}(\varepsilon=7.80)$; ethanol $(\varepsilon=24.55)$; DMF $(\varepsilon=38.00)$ and water $(\varepsilon=78.4)$ and the dipole moments are sensitive to the polarity of the medium. The calculated dipole moments are substantially higher in a medium of high relative permittivity, mainly due to major charge redistribution in the molecule, and also by changes in the distances between the charge separations. The magnitude of the influence of the solvent reaction field on electronic structure is different in different tautomers. This may also explain the great variation of the calculated dipole moments of the tautomers.

The CA8 tautomer has the largest dipole moment and the CA11 has the smallest dipole moment in all phases. Having the largest dipole moment the CA8 tautomer is expected to have the strongest interaction with polar molecules of water in biological environment. The structure of a tautomer obviously affects the magnitude and orientation of a dipole moment. For example, a transition from an keto- to a enol- form usually leads to an increase of the dipole moment, and upon a transition from one enol form of CA11 and tautomer to the keto form of CA1 form we observe 0.0002 and $0.0013 \mathrm{D}$ dipole moment change respectively. However, the position of hydrogen attached to $\mathrm{O}$ in the ring of cyanuric acid has much greater influence on the dipole moment. Not only does it affect the magnitude of the dipole moment but it even changes its orientation. This is indicated by the fact that the orientation of dipole moments in the CA2 and CA3, tautomers of cynuric acid with $\mathrm{H}$ attached to the $\mathrm{O}$ atom is almost opposite, and the similar effect to absevered in all cynuric acid tautomers. The calculated dipole moments for the studied tautomers at the HF/6-311++G $(d, p)$ level in solution are given in Table 2. The order of the dipole moment of tautomers in gas phase is CA11 > CA1 > CA10 > CA4 > CA3 > CA6 > CA2 > CA5 > CA7 > CA9 > CA8. The figure 3shows the effect of solvents on dipole movements for tautomers of cynuric acid. The two tautomers CA8 and CA9have large magnitude in total energy differences in gas phase and large dipole moments (Table 2). This leads to the inversion of their order of stability in polar solvent. 
Table.2. The zero dipole moments $(\mu)$ in Debye units,Polarizability $(\alpha)$ and Mean Polarizability $\langle\alpha\rangle$ for the tautomers at $H F / 6-311++G(d, p)$ level in different solvents.

\begin{tabular}{|c|c|c|c|c|c|c|c|c|c|c|c|}
\hline \multirow{2}{*}{$\begin{array}{l}\text { Polariza } \\
\text { bility( } \alpha)\end{array}$} & \multicolumn{11}{|c|}{ Gas $(\varepsilon=1.00)$} \\
\hline & CA1 & CA2 & CA3 & CA4 & CA5 & CA6 & CA7 & CA8 & CA9 & CA10 & CA11 \\
\hline$\alpha x x$ & 65.860 & 65.634 & 62.378 & 66.908 & 67.082 & 64.071 & 67.295 & 56.290 & 59.935 & 70.870 & 67.941 \\
\hline ayy & 65.856 & 70.256 & 72.878 & 70.768 & 71.026 & 73.201 & 70.464 & 83.688 & 78.115 & 65.065 & 67.935 \\
\hline$\alpha z z$ & 31.924 & 32.632 & 32.666 & 33.295 & 33.307 & 33.330 & 33.339 & 34.609 & 33.643 & 33.881 & 33.883 \\
\hline$\langle\alpha\rangle$ & 54.547 & 56.174 & 55.974 & 56.990 & 57.138 & 56.867 & 57.033 & 58.196 & 57.231 & 56.605 & 56.586 \\
\hline \multirow[t]{2}{*}{$\mu$} & 0.0013 & 6.0137 & 4.1201 & 4.1018 & 6.7086 & 4.3529 & 7.4374 & 10.8363 & 9.3673 & 3.1097 & 0.0002 \\
\hline & \multicolumn{11}{|c|}{$\operatorname{THF}(\varepsilon=7.50)$} \\
\hline$\alpha x x$ & 78.972 & 78.015 & 74.486 & 79.220 & 79.772 & 76.670 & 79.548 & 68.232 & 71.891 & 84.845 & 82.286 \\
\hline ayy & 78.957 & 86.136 & 88.788 & 87.372 & 87.345 & 89.465 & 87.097 & 100.298 & 95.794 & 79.719 & 82.298 \\
\hline$\alpha z z$ & 37.232 & 38.287 & 38.313 & 39.313 & 39.321 & 39.323 & 39.338 & 39.530 & 39.576 & 40.211 & 40.221 \\
\hline$\langle\alpha\rangle$ & 65.054 & 67.479 & 67.196 & 68.635 & 68.813 & 68.486 & 68.661 & 69.353 & 69.087 & 68.258 & 68.268 \\
\hline \multirow[t]{2}{*}{$\mu$} & 0.002 & 7.8617 & 5.3943 & 5.292 & 8.4879 & 5.6696 & 9.4292 & 15.4215 & 12.4961 & 3.7619 & 0.002 \\
\hline & \multicolumn{11}{|c|}{ ethanol $(\varepsilon=1.00)$} \\
\hline$\alpha x x$ & 81.259 & 80.138 & 76.678 & 81.380 & 81.978 & 78.989 & 81.797 & 70.828 & 74.285 & 87.299 & 84.935 \\
\hline ayy & 81.262 & 89.103 & 91.654 & 90.530 & 90.455 & 92.441 & 90.115 & 103.202 & 98.885 & 82.582 & 84.923 \\
\hline$\alpha z z$ & 38.570 & 39.715 & 39.744 & 40.843 & 40.844 & 40.844 & 40.857 & 41.086 & 41.111 & 41.809 & 35.701 \\
\hline$\langle\alpha\rangle$ & 67.030 & 69.652 & 69.359 & 70.918 & 71.092 & 70.758 & 70.923 & 71.705 & 71.427 & 70.563 & 68.520 \\
\hline \multirow[t]{2}{*}{$\mu$} & 0.0066 & 8.232 & 5.6339 & 5.5251 & 8.8437 & 5.9109 & 9.8141 & 16.1875 & 13.1161 & 3.9005 & 0.0018 \\
\hline & \multicolumn{11}{|c|}{$\operatorname{DMF}(\varepsilon=24.55)$} \\
\hline$\alpha x x$ & 81.776 & 80.591 & 77.141 & 81.846 & 82.453 & 79.493 & 82.283 & 71.415 & 74.811 & 87.826 & 85.530 \\
\hline ayy & 81.775 & 89.749 & 92.257 & 91.220 & 91.135 & 93.086 & 90.771 & 103.813 & 99.551 & 83.212 & 85.544 \\
\hline$\alpha z z$ & 38.875 & 40.045 & 40.074 & 41.197 & 41.197 & 41.197 & 41.209 & 41.449 & 41.467 & 42.179 & 42.207 \\
\hline$\langle\alpha\rangle$ & 67.475 & 70.128 & 69.824 & 71.421 & 71.595 & 71.259 & 71.421 & 72.226 & 71.943 & 71.072 & 71.094 \\
\hline \multirow[t]{2}{*}{$\mu$} & 0.0032 & 8.3138 & 5.6741 & 5.5761 & 8.9217 & 5.9634 & 9.8991 & 16.3567 & 13.2529 & 3.9314 & 0.0011 \\
\hline & \multicolumn{11}{|c|}{ water $(\varepsilon=78.50)$} \\
\hline$\alpha x x$ & 82.013 & 80.800 & 77.361 & 82.061 & 82.674 & 79.728 & 82.509 & 71.688 & 75.058 & 88.071 & 85.775 \\
\hline ayy & 81.998 & 90.050 & 92.544 & 91.540 & 91.451 & 93.386 & 91.077 & 104.094 & 99.858 & 83.506 & 85.786 \\
\hline$\alpha z z$ & 39.019 & 34.031 & 40.231 & 41.365 & 41.364 & 41.363 & 41.375 & 41.621 & 41.635 & 42.354 & 35.692 \\
\hline$\langle\alpha\rangle$ & 67.677 & 68.294 & 70.045 & 71.655 & 71.830 & 71.492 & 71.654 & 72.468 & 72.184 & 71.310 & 69.084 \\
\hline$\mu$ & 0.0023 & 8.3519 & 5.698 & 5.5998 & 8.9582 & 5.9877 & 9.939 & 16.4354 & 13.3169 & 3.9459 & 0.0019 \\
\hline
\end{tabular}

\section{MOLECULAR POLARIZABILITY}

The Polarizability calculations carried out for different solvents effects on cynuric acid tautomers are summarized in table 2. Here, $\alpha$ is a second rank tensor property called the dipole Polarizability and mean Polarizability $\langle\alpha\rangle$ are evaluated using

$$
\langle\alpha\rangle=\frac{1}{3}\left(\alpha_{x x}+\alpha_{y y}+\alpha_{z z}\right)
$$


When a molecule is placed in a liquid environment, it is polarized, i.e., its electrostatic moments are changed giving rise to induced multipole moments. The amount of polarization will depend on several factors including, of course, the Polarizability of the solute and the electric field provided by the environment. As seen from the Figure 4. inthe gas phase the polarizabilities are low and in all the solvents are high values, the order of polarizabilities is Gas $>$ THF $>$ ethanol $>$ DMF > water, due to increase of dielectric constant of solvents. The largest Polarizability was observed for CA8 tautomer in all phases.CA8 tautomer is more polarizable than other tautomers because of its dipole moment is high value in all solvents.

\section{ENERGETICS}

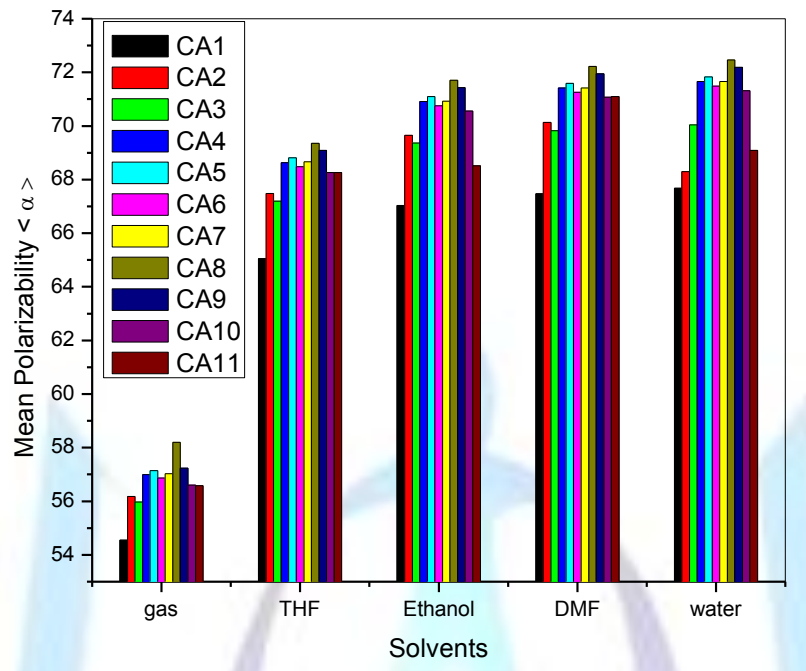

Figure 4.PolarizablitiesVs Solvents

Thermodynamic and kinetic factors are important to the understanding of tautomeric equlibria and their impact on biology. The enthalpies, entropies and Gibbs free energies for the tautomers of cynuricacid are given inTables 3 .in different solvents. The change of enthalpy $(\mathbf{\Delta H})$ and the free energy $(\boldsymbol{\Delta G})$ changeare positivein all phases of the conversion from CA1 to other tautomersand are endothermic and non spontaneous process respectively.

Table .3. The calculated thermodynamic properties for tautomers of Cynuric acid in gas phase and different solvents by using $\mathrm{HF} / 6-311++\mathrm{G}(\mathrm{d}, \mathrm{p})$ at $298.15 \mathrm{~K}$

\begin{tabular}{|c|c|c|c|c|c|c|c|c|c|c|c|c|c|c|c|}
\hline \multirow{2}{*}{ Tautomer } & \multicolumn{3}{|c|}{$\operatorname{gas}(\varepsilon=1.00)$} & \multicolumn{3}{|c|}{$\operatorname{THF}(\varepsilon=7.50)$} & \multicolumn{3}{|c|}{ ethanol $(\varepsilon=1.00)$} & \multicolumn{3}{|c|}{$\operatorname{DMF}(\varepsilon=24.55)$} & \multicolumn{3}{|c|}{ water $(\varepsilon=78.50)$} \\
\hline & $\Delta \mathrm{H}$ & $\Delta \mathbf{G}$ & $\Delta S$ & $\Delta \mathbf{H}$ & $\Delta \mathbf{G}$ & $\Delta \mathbf{S}$ & $\Delta \mathbf{H}$ & $\Delta \mathbf{G}$ & $\Delta S$ & $\Delta \mathbf{H}$ & $\Delta \mathbf{G}$ & $\Delta \mathbf{S}$ & $\Delta \mathbf{H}$ & $\Delta \mathbf{G}$ & $\Delta \mathbf{S}$ \\
\hline $\mathrm{CA} 1 \leftrightarrow \mathrm{CA} 2$ & 27.78 & 27.32 & 1.554 & 21.45 & 21.83 & -1.278 & 20.12 & 20.44 & -1.085 & 19.80 & 20.18 & -1.295 & 19.65 & 20.05 & -1.324 \\
\hline $\mathrm{CA} 1 \leftrightarrow \mathrm{CA} 3$ & 17.53 & 17.75 & -0.767 & 16.08 & 16.28 & -0.688 & 15.77 & 15.92 & -0.497 & 15.68 & 15.89 & -0.701 & 15.64 & 15.86 & -0.733 \\
\hline $\mathrm{CA} 1 \leftrightarrow \mathrm{CA} 4$ & 37.17 & 37.44 & -0.888 & 32.34 & 32.58 & -0.803 & 31.24 & 31.45 & -0.717 & 30.97 & 31.25 & -0.952 & 30.85 & 31.15 & -0.993 \\
\hline CA1↔CA5 & 38.83 & 63.58 & -0.747 & 33.26 & 33.67 & -1.386 & 31.92 & 32.24 & -1.084 & 31.59 & 31.97 & -1.257 & 31.45 & 31.82 & -1.268 \\
\hline $\mathrm{CA} 1 \leftrightarrow \mathrm{CA} 6$ & 28.51 & 29.08 & $\begin{array}{l}-1.893 \\
\end{array}$ & 27.30 & 27.75 & -1.496 & 27.02 & 27.40 & -1.269 & 26.94 & 27.38 & -1.474 & 26.90 & 27.35 & -1.502 \\
\hline $\mathrm{CA} 1 \leftrightarrow \mathrm{CA} 7$ & 31.32 & 31.80 & -1.614 & 28.50 & 28.93 & -1.455 & 27.81 & 28.17 & -1.227 & 27.63 & 28.06 & -1.437 & 27.55 & 27.99 & -1.467 \\
\hline $\mathrm{CA} 1 \leftrightarrow \mathrm{CA} 8$ & 61.70 & 61.23 & 1.556 & 48.30 & 47.59 & 2.354 & 44.93 & 44.50 & 1.428 & 44.14 & 43.88 & 0.857 & 43.78 & 43.57 & 0.678 \\
\hline $\mathrm{CA} 1 \leftrightarrow \mathrm{CA} 9$ & 50.31 & 49.48 & 2.793 & 41.36 & 40.63 & 2.449 & 39.34 & 39.18 & 0.561 & 38.87 & 38.83 & 0.118 & 38.65 & 38.65 & -0.007 \\
\hline $\mathrm{CA} 1 \leftrightarrow \mathrm{CA} 10$ & 29.34 & 30.15 & -2.725 & 30.85 & 31.47 & -2.083 & 30.99 & 31.53 & -1.818 & 30.99 & 31.59 & -2.016 & 31.00 & 31.61 & -2.04 \\
\hline $\mathrm{CA} 1 \leftrightarrow \mathrm{CA} 11$ & 28.22 & 29.06 & -2.806 & 30.50 & 31.15 & -2.18 & 30.82 & 31.36 & -1.816 & 30.87 & 31.51 & -2.146 & 30.88 & 31.49 & -2.033 \\
\hline
\end{tabular}

\section{TAUTOMERIC EQUILIBRIA IN THE GAS PHASE AND SOLUTION}

Cyanuric acid exists mainly in eleven tautomeric forms (CA1- CA11) that are in equilibrium. CA1 has a keto form and can be converted to CA2 and CA3 tautomers through a proton transfer and rotation around the C-O bond, simultaneously. The CA4 to CA9 isomers give the dihydroxy form by two protons transfer and considering the orientation of the hydroxyl 
hydrogen's. CA10 and CA11 are converted try hydroxyl isomers through three proton transfer.Therefore, only eleven isomers were considered in the present study.

The HF method calculated tautomeric equilibrium constants with respect to the most stable tautomer CA1 of Cyanuric acid both in the gas and in different solution are listed in Table 3 . The tautomeric equilibrium between tautomers a and $b$ is described as

$$
a \square b
$$

Equilibrium constants for each species were calculated by using the following equation

$$
K_{T}=e^{-(\Delta G / R T)}
$$

Where $\mathrm{K}_{\mathrm{T}}$ is the tautomeric equilibrium constant between the tautomers, the gas constant $\mathrm{R}$ is $1.987 \times 10^{-3} \mathrm{kcal} / \mathrm{mol}$; and the temperature $\mathrm{T}$ is $298.15 \mathrm{~K}$. The $p K_{T}$ values of the studied molecules were calculated by means of the following equation

$$
p K_{T}=\frac{\Delta G}{2.303 R T}
$$

The equilibrium between the tautomers 1 and 3 of cyanuric acid values for show that the CA2 is more dominant than the CA3, both for the gas and different solvents with a $\mathrm{pK}_{\mathrm{T}}$ value of 13.0,(gas) and 11.93(THF) , 11.66 (ethanol),11.64 DMF and 13.01 (water) respectively. This is confirm to thermodynamic data of CA1 $\leftrightarrow$ CA3, see the table 3 . The remaining tautomers are not detectable amounts because of the $p K_{T}$ values are very high.

From the Table 4 the $p K_{T}$ values are decreasing with increase in polarity of solvents. Solvent effects have been ascribed to two major components ${ }^{[18]}$, electrostatic solvent-solute interaction and hydrogen bonding. The hydrogen bonding effects cannot be estimated in a quantitative manner from the salvation model, and needs further large-scale calculations. The electrostatic solvent-solute effects, however, are readily estimated by the reaction field continuum model ${ }^{[19]}$ using the dipole moments and molecular polarizabilities. Application of the reaction field continuum model leads to an explanation of the change in order of tautomeric stability on going from gas phase to solution. However, such a treatment lacks explicit consideration of base-water hydrogen bonding effects ${ }^{[20]}$.

From the interconversiondiagram, to evaluate in a more realistic way theconstants of equilibriums as represented in Figure. 5. Table 5 contained the $p K_{T}$ of the equilibrium constants calculated starting from the general outline of interconversion. Some $p K_{T}$ were positive and the other negative; that determinate the privileged direction of equilibrium. If the $p K_{T}$ was positive, equilibrium moved from right towards the left and when it was negative, equilibrium moved from left towards the right. By taking account of all these directions of displacement, we obtained.

\begin{tabular}{|c|c|c|c|c|c|c|c|c|c|c|}
\hline \multirow{2}{*}{ Tautomer } & \multicolumn{2}{|c|}{$\operatorname{gas}(\varepsilon=1.00)$} & \multicolumn{2}{|c|}{$\operatorname{THF}(\varepsilon=7.50)$} & \multicolumn{2}{|c|}{ ethanol $(\varepsilon=1.00)$} & \multicolumn{2}{|c|}{$\operatorname{DMF}(\varepsilon=24.55)$} & \multicolumn{2}{|c|}{ water $(\varepsilon=78.50)$} \\
\hline & K & $p K_{T}$ & K & $p K_{T}$ & K & $p K_{T}$ & K & $p K_{T}$ & K & $p K_{T}$ \\
\hline $\mathrm{CA} 1 \leftrightarrow \mathrm{CA} 2$ & $9.4148 \times 10^{-21}$ & 20.0262 & $\begin{array}{c}9.9565 \times 1 \\
0^{-17}\end{array}$ & 16.0019 & $\underset{25}{1.0399 \times 10}$ & 14.9830 & $1.6128 \times 10^{-}$ & 14.7924 & $2.0085 \times 10$ & 14.6971 \\
\hline $\mathrm{CA} 1 \leftrightarrow \mathrm{CA} 3$ & $9.7463 \times 10^{-14}$ & 13.0112 & $\begin{array}{c}1.1651 \times 1 \\
0^{-12}\end{array}$ & 11.9336 & $\underset{12}{2.1393 \times 10}$ & 11.6697 & $2.2504 \times 10^{-}$ & 11.6477 & $\underset{12}{2.3673 \times 10}$ & 11.6257 \\
\hline $\mathrm{CA} 1 \leftrightarrow \mathrm{CA} 4$ & $3.5943 \times 10^{-28}$ & 27.4444 & $\begin{array}{c}1.3125 \times 1 \\
0^{-24}\end{array}$ & 23.8819 & $\begin{array}{l}8.8390 \\
\times 10^{-24}\end{array}$ & 23.0536 & $1.2388 \times 10^{-}$ & 22.9070 & $1.466 \underset{23}{6} \times 10$ & 22.8337 \\
\hline $\mathrm{CA} 1 \leftrightarrow \mathrm{CA} 5$ & $2.4797 \times 10^{-47}$ & 46.6056 & $\begin{array}{c}2.0850 \times 1 \\
0^{-25}\end{array}$ & 24.6809 & $2.3299 \times 10$ & 23.6327 & $3.6749 \times 10^{-}$ & 23.4347 & $4.7337 \times 24 \times 10$ & 23.3248 \\
\hline $\mathrm{CA} 1 \leftrightarrow \mathrm{CA} 6$ & $4.8271 \times 10^{-22}$ & 21.3163 & $\begin{array}{c}4.5563 \times 1 \\
0^{-21}\end{array}$ & 20.3414 & $\underbrace{8.2256 \times 10}_{21}$ & 20.0848 & $\underset{21}{8.5080 \times 10^{-}}$ & 20.0702 & $8.94999 \times 10$ & 20.0482 \\
\hline $\mathrm{CA} 1 \leftrightarrow \mathrm{CA} 7$ & $4.8963 \times 10^{-24}$ & 23.3101 & $\begin{array}{c}6.2179 \times 1 \\
0^{-22}\end{array}$ & 21.2064 & $2.2425 \times 10^{-1}$ & 20.6493 & $2.7000 \times 10^{-}$ & 20.5686 & $3.0387 \times 10$ & 20.5173 \\
\hline CA1↔CA8 & $1.3091 \times 10^{-45}$ & 44.8830 & $1.3044 \times 1$ & 34.8846 & $2.4014 \times 10^{-}$ & 32.6195 & $6.8383 \times 10^{-}$ & 32.1650 & $1.1539 \times 10^{-}$ & 31.9378 \\
\hline
\end{tabular}

Table 4. HF/6-31++ $\mathrm{G}(\mathrm{d}, \mathrm{p})$ predicted tautomeric equilibrium constants ( $p K_{T}$ ) with respect to the most stable tautomer of CA1 in the gas phase and different solvents at $298.15 \mathrm{~K}$ 
ISSN 2321-807X

\begin{tabular}{|c|c|c|c|c|c|c|c|c|c|c|}
\hline & & & $0^{-35}$ & & & & & & & \\
\hline $\mathrm{CA} 1 \leftrightarrow \mathrm{CA} 9$ & $5.3706 \times 10^{-37}$ & 36.2700 & $\begin{array}{c}1.6492 \times 1 \\
0^{-30}\end{array}$ & 29.7827 & $1_{29}^{1.9061 \times 10}$ & 28.7198 & $3.4412 \times 10^{-}$ & 28.4633 & $4.6629 \times 10^{-}$ & 28.3313 \\
\hline $\mathrm{CA} 1 \leftrightarrow \mathrm{CA} 10$ & $7.9315 \times 10^{-23}$ & 22.1006 & $\begin{array}{c}8.5460 \times 1 \\
0^{-24}\end{array}$ & 23.0682 & $\begin{array}{c}7.7230 \times 10 \\
24\end{array}$ & 23.1122 & $6.9791 \times 10^{-}$ & 23.1562 & $\underbrace{6.7475 \times 10^{-}}_{24}$ & 23.1709 \\
\hline $\mathrm{CA} 1 \leftrightarrow \mathrm{CA} 11$ & $4.9929 \times 10^{-22}$ & 21.3016 & $\begin{array}{c}1.4666 \times 1 \\
0^{-23}\end{array}$ & 22.8337 & ${ }_{23}^{1.0289 \times 10^{0}}$ & 22.9876 & $7.988_{24} 1 \times 10^{-1}$ & 23.0976 & $8.2624 \times 10^{-1}$ & 23.0829 \\
\hline
\end{tabular}

Table .5..HF/6-311++G(d,p) predicted tautomeric equilibrium constants $\left(p K_{T}\right)$ with respect to the most stable tautomer of CA1 in the gas phase and different solvents from the interconversion diagram at $298.15 \mathrm{~K}$

\begin{tabular}{|c|c|c|c|c|c|c|c|c|c|c|}
\hline \multirow{2}{*}{ Tautomer } & \multicolumn{2}{|c|}{ gas $(\varepsilon=1.00)$} & \multicolumn{2}{|c|}{$\operatorname{THF}(\varepsilon=7.50)$} & \multicolumn{2}{|c|}{ ethanol $(\varepsilon=1.00)$} & \multicolumn{2}{|c|}{$\operatorname{DMF}(\varepsilon=24.55)$} & \multicolumn{2}{|c|}{ water $(\varepsilon=78.50)$} \\
\hline & K & $p K_{T}$ & K & $p K_{T}$ & K & $p K_{T}$ & K & $p K_{T}$ & K & $p K_{T}$ \\
\hline $\mathrm{CA} 2 \leftrightarrow \mathrm{CA} 3$ & $1.0178 \times 10^{7}$ & -7.0077 & $1.1702 \times 10^{4}$ & $\mid-4.0683$ & $2.0921 \times 10$ & -3.3206 & 1.3953 & -3.1447 & 1.158 & -3.0640 \\
\hline $\mathrm{CA} 2 \leftrightarrow \mathrm{CA} 4$ & $3.8177 \times 10^{-8}$ & 7.4182 & $1.3182 \times 10^{-8}$ & 7.8800 & $\underset{9}{8.4999 \times 10^{-}}$ & 8.0706 & $\begin{array}{c}7.6813 \\
9\end{array}$ & 1146 & $7.3020 \times 10^{-}$ & 8.1366 \\
\hline $\mathrm{CA} 2 \leftrightarrow \mathrm{CA} 5$ & $2.5897 \times 10^{27}$ & \begin{tabular}{|l|}
26.586 \\
7
\end{tabular} & $0941 \times 10^{-9}$ & 8.6790 & $2.2404 \times 10^{-}$ & 8.6497 & $7.6813 \times 10^{-}$ & 8.1146 & $2.3173 \times 10^{-}$ & 8.6350 \\
\hline $\mathrm{CA} 2 \leftrightarrow \mathrm{CA} 6$ & $1271 \times 10^{-2}$ & 1.2901 & $4.5761 \times 10^{-5}$ & 4.3395 & $7.9097 \times 10^{-}$ & 5.1018 & $5.3649 \times 10^{-}$ & 5.2704 & 4.4558 & 5.3511 \\
\hline $\mathrm{CA} 2 \leftrightarrow \mathrm{CA} 8$ & $1.3672 \times 10^{-25}$ & \begin{tabular}{|c|}
24.864 \\
1
\end{tabular} & $\underset{19}{3101 \times 10-}$ & $\begin{array}{c}18.882 \\
7\end{array}$ & $\begin{array}{c}2.3485 x \\
10^{-18}\end{array}$ & $\begin{array}{c}17.629 \\
2\end{array}$ & $\underset{18}{4.2399 \times 10^{-}}$ & $\begin{array}{c}17.372 \\
6\end{array}$ & $\underbrace{5.6489 \times 10^{-}}_{18}$ & 17.2480 \\
\hline $\mathrm{CA} 2 \leftrightarrow \mathrm{CA} 10$ & $2835 \times 10^{-3}$ & 2.0818 & $8.5833 \times 10^{-8}$ & 7.0663 & $\underset{9}{7.4263 \times 10^{-}}$ & 8.1292 & $\underset{9}{4.3272 \times 10^{-}}$ & 8.3638 & $3.3593 \times 10^{-}$ & 8.4737 \\
\hline $\mathrm{CA} 3 \leftrightarrow \mathrm{CA} 4$ & $3.7506 \times 10^{-15}$ & $\begin{array}{c}14.425 \\
9\end{array}$ & $1264 \times 10^{-}$ & $\begin{array}{c}11.948 \\
3\end{array}$ & $4.0627 \times 10^{-1}$ & \begin{tabular}{|c|}
11.391 \\
2
\end{tabular} & $5.5051 \times 10^{-}$ & $\begin{array}{c}11.259 \\
2\end{array}$ & $6.3009 \times 10^{-}$ & 11.2006 \\
\hline $\mathrm{CA} 3 \leftrightarrow \mathrm{CA} 6$ & $.0370 \times 10^{-9}$ & 8.2978 & $3.9104 \times 10^{-9}$ & 8.4078 & $3.8450 \times 10^{-}$ & 8.4151 & $3.7806 \times 10^{-1}$ & 8.4224 & 3.780 & 8.4224 \\
\hline $\mathrm{CA} 3 \leftrightarrow \mathrm{CA} 5$ & $2.5442 \times 10^{-34}$ & $\begin{array}{c}33.594 \\
4\end{array}$ & ${ }_{13}^{1.7895} \times 10^{-}$ & $\begin{array}{c}12.747 \\
3\end{array}$ & $\operatorname{lin}_{12}^{1.0708 \times 10^{-}}$ & $\begin{array}{c}11.970 \\
3\end{array}$ & $5.5051 \times 10^{-}$ & $\begin{array}{c}11.259 \\
2\end{array}$ & $3.7806 \times 10^{-}$ & 8.4224 \\
\hline $\mathrm{CA} 3 \leftrightarrow \mathrm{CA} 7$ & $5.1092 \times 10^{-11}$ & $\begin{array}{c}10.291 \\
6\end{array}$ & $\underset{10}{5.3365 \times 10^{-}}$ & 9.2727 & $\underset{9}{1.0307 \times 10^{-}}$ & 8.9869 & 1.199 & 8.9209 & 1.283 & 8.8916 \\
\hline $\mathrm{CA} 3 \leftrightarrow \mathrm{CA} 9$ & $5.5103 \times 10^{-24}$ & $\begin{array}{c}23.258 \\
8\end{array}$ & $1.4154 \times 10^{-}$ & $\begin{array}{c}17.849 \\
1\end{array}$ & $8.91 \underset{18}{0.1} \times 10^{-}$ & $\begin{array}{c}17.050 \\
1\end{array}$ & $1.5291 \times 10^{-}$ & $\begin{array}{c}16.815 \\
5\end{array}$ & $1.9697 \times 10^{-}$ & 16.7056 \\
\hline $\mathrm{CA} 3 \leftrightarrow \mathrm{CA} 11$ & $0^{-9}$ & 32 & ${ }_{11}^{1.2587 \times 10^{-}}$ & $\begin{array}{c}10.900 \\
1\end{array}$ & $4.80972 \times 10^{-}$ & $\begin{array}{c}11.317 \\
9\end{array}$ & $3.549_{1}$ & $\begin{array}{c}11.449 \\
8\end{array}$ & $3.4902 \times 10^{-}$ & 11.4571 \\
\hline $\mathrm{CA} 4 \leftrightarrow \mathrm{CA} 6$ & $1.3429 \times 10^{6}$ & -6.1281 & $3.4713 \times 10^{3}$ & -3.5405 & $9.3055 \times 10$ & -2.9687 & $6.9843 \times 10$ & -2.8441 & $6.1022 \times 10$ & -2.7855 \\
\hline $\mathrm{CA} 4 \leftrightarrow \mathrm{CA} 10$ & $2.1697 \times 10^{5}$ & -5.3364 & 6.4021 & -0.8063 & $8.7369 \times 10^{-}$ & 0.0586 & $5.6334 \times 10^{-}$ & 0.2492 & $4.6005 \times 10^{-}$ & 0.3372 \\
\hline $\mathrm{CA} 4 \leftrightarrow \mathrm{CA} 8$ & $3.5814 \times 10^{-18}$ & $\begin{array}{c}17.445 \\
9\end{array}$ & 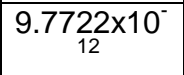 & $\begin{array}{c}11.010 \\
0\end{array}$ & ${ }^{2.7167 \times 10^{-}}$ & 9.5659 & $5.5197 \times 10^{-}$ & 9.2581 & $\underbrace{7.7361 \times 10^{-}}_{10}$ & 9.1115 \\
\hline $\mathrm{CA} 5 \leftrightarrow \mathrm{CA} 6$ & $1.9798 \times 10^{25}$ & $\begin{array}{c}- \\
25.2966\end{array}$ & $2.2224 \times 10^{4}$ & -4.3468 & $3.5304 \times 10$ & -3.5478 & $\underset{2}{6.9843 \times 10}$ & -2.8441 & $\underset{3}{1.8906 \times 10}$ & -3.2766 \\
\hline $\mathrm{CA} 5 \leftrightarrow \mathrm{CA} 9$ & $\begin{array}{c}2202693244 \\
8\end{array}$ & 10.3430 & $8.0443 \times 10^{-6}$ & 5.0945 & $8.3205 \times 10^{-}$ & 5.0798 & $2.7777 \times 10^{-}$ & 5.5563 & $\underset{6}{9.8503 \times 10^{-}}$ & 5.0065 \\
\hline $\mathrm{CA} 5 \leftrightarrow \mathrm{CA} 11$ & $2.0477 \times 10^{25}$ & 25.3113 & $7.0342 \times 10^{1}$ & -1.8472 & 4.4914 & -0.6524 & $6.4478 \times 10^{-}$ & 0.1906 & 1.7751 & -0.2492 \\
\hline $\mathrm{CA} 6 \leftrightarrow \mathrm{CA} 7$ & $1.0143 \times 10^{-2}$ & 1.9938 & $1.3418 \times 10^{-1}$ & \begin{tabular}{|l|}
0.8723 \\
\end{tabular} & $2.7262 \times 10^{-}$ & 0.5644 & $3.1735 \times 10^{-}$ & 0.4985 & $3.3951 \times 10^{-}$ & 0.4691 \\
\hline
\end{tabular}


ISSN 2321-807X

\begin{tabular}{|c|c|c|c|c|c|c|c|c|c|c|}
\hline \multirow{2}{*}{ Tautomer } & \multicolumn{2}{|c|}{$\operatorname{gas}(\varepsilon=1.00)$} & \multicolumn{2}{|c|}{$\operatorname{THF}(\varepsilon=7.50)$} & \multicolumn{2}{|c|}{ ethanol $(\varepsilon=1.00)$} & \multicolumn{2}{|c|}{$\operatorname{DMF}(\varepsilon=24.55)$} & \multicolumn{2}{|c|}{ water $(\varepsilon=78.50)$} \\
\hline & K & $p K_{T}$ & K & $p K_{T}$ & K & $p K_{T}$ & K & $p K_{T}$ & K & $p K_{T}$ \\
\hline & & & & & & & & & & \\
\hline $\mathrm{CA} 6 \leftrightarrow \mathrm{CA} 10$ & $1.6156 \times 10^{-1}$ & 0.7917 & $1.8442 \times 10^{-3}$ & 2.7342 & $\underset{4}{9.3889 \times 10}$ & 3.0274 & $8.0657 \times 10$ & 3.0934 & $7.5391 \times 10^{-}$ & 3.1227 \\
\hline $\mathrm{CA} 6 \leftrightarrow \mathrm{CA} 11$ & 1.0343 & -0.0147 & $3.2190 \times 10^{-}$ & 2.4923 & $1.2509 \times 10$ & 2.9028 & $9.2317 \times 10^{-}$ & 3.0347 & $9.2317 \times 10^{-}$ & 3.0347 \\
\hline $\mathrm{CA} 6 \leftrightarrow \mathrm{CA} 8$ & $2.6667 \times 10^{-24}$ & $\begin{array}{c}23.574 \\
0\end{array}$ & $2.8151 \times 10^{-}$ & \begin{tabular}{|l}
14.550 \\
5
\end{tabular} & $\underset{13}{2.9194 \times 10}$ & $\begin{array}{c}12.534 \\
7\end{array}$ & $\underset{13}{7.9029 \times 10}$ & $\begin{array}{c}12.102 \\
2\end{array}$ & $\underbrace{1.2893 \times 10^{-}}_{12}$ & 11.8896 \\
\hline $\mathrm{CA} 7 \leftrightarrow \mathrm{CA} 7$ & $1.0968 \times 10^{-13}$ & $\begin{array}{c}12.959 \\
8\end{array}$ & $2.6975 \times 10^{-9}$ & 8.5690 & $\underset{9}{8.6446 \times 10}$ & 8.0633 & $\underset{8}{1.2745 \times 10}$ & 7.8947 & $1.5345 \times 10^{-}$ & 7.8140 \\
\hline $\mathrm{CA} 7 \leftrightarrow \mathrm{CA} 11$ & $1.0197 \times 10^{2}$ & -2.0085 & $2.3587 \times 10^{-2}$ & 1.6273 & $\underset{3}{4.6664 \times 10}$ & 2.3310 & $2.9584 \times 10$ & 2.5289 & $2.7190 \times 10^{-}$ & 2.5656 \\
\hline $\mathrm{CA} 8 \leftrightarrow \mathrm{CA} 9$ & $4.1720 \times 10^{8}$ & -8.6204 & $1.2857 \times 10^{5}$ & $\mid-5.1092$ & $\underset{3}{7.9374 \times 10}$ & $\mid-3.8997$ & $5.0322 \times 10$ & -3.7018 & $4.0408 \times 10$ & -3.6065 \\
\hline $\mathrm{CA} 8 \leftrightarrow \mathrm{CA} 10$ & $6.0583 \times 10^{22}$ & $\begin{array}{c}- \\
22.7824\end{array}$ & $6.5513 \times 10^{1}$ & 11.8163 & $3.2159 \times 10$ & -9.5073 & $1.0205 \times 10$ & -9.0089 & $5.9468 \times 10$ & -8.7743 \\
\hline $\mathrm{CA} 8 \leftrightarrow \mathrm{CA} 11$ & $3.8786 \times 10^{23}$ & 23.5887 & $1.1243 \times 10^{1}$ & 12.0509 & $4.2847 \times 10$ & -9.6319 & $1.16891 \times 10$ & -9.0675 & $7.2819 \times 10$ & -8.8622 \\
\hline $\mathrm{CA} 9 \leftrightarrow \mathrm{CA} 10$ & $1.4768 \times 10^{14}$ & 14.1693 & $5.0951 \times 10^{6}$ & -6.7072 & $4.05 \underset{5}{15 \times 10}$ & -5.6076 & $2.0280 \times 10$ & -5.3071 & $1.47{ }_{5}^{16 \times 10}$ & -5.1678 \\
\hline $\mathrm{CA} 9 \leftrightarrow \mathrm{CA} 11$ & $9.2967 \times 10^{14}$ & $14 . \overline{-}$ & $8.8931 \times 10^{6}$ & -6.9491 & $\underset{5}{5.3980 \times 10}$ & -5.7322 & $2.3212 \times 10$ & -5.3657 & $1.8020 \times 10$ & -5.2558 \\
\hline $\begin{array}{c}\mathrm{CA} 10 \leftrightarrow \mathrm{CA} 1 \\
1\end{array}$ & 6.4021 & -0.8063 & 1.7161 & -0.2346 & 1.3323 & -0.1246 & 1.1445 & -0.0586 & 1.2245 & -0.0880 \\
\hline
\end{tabular}




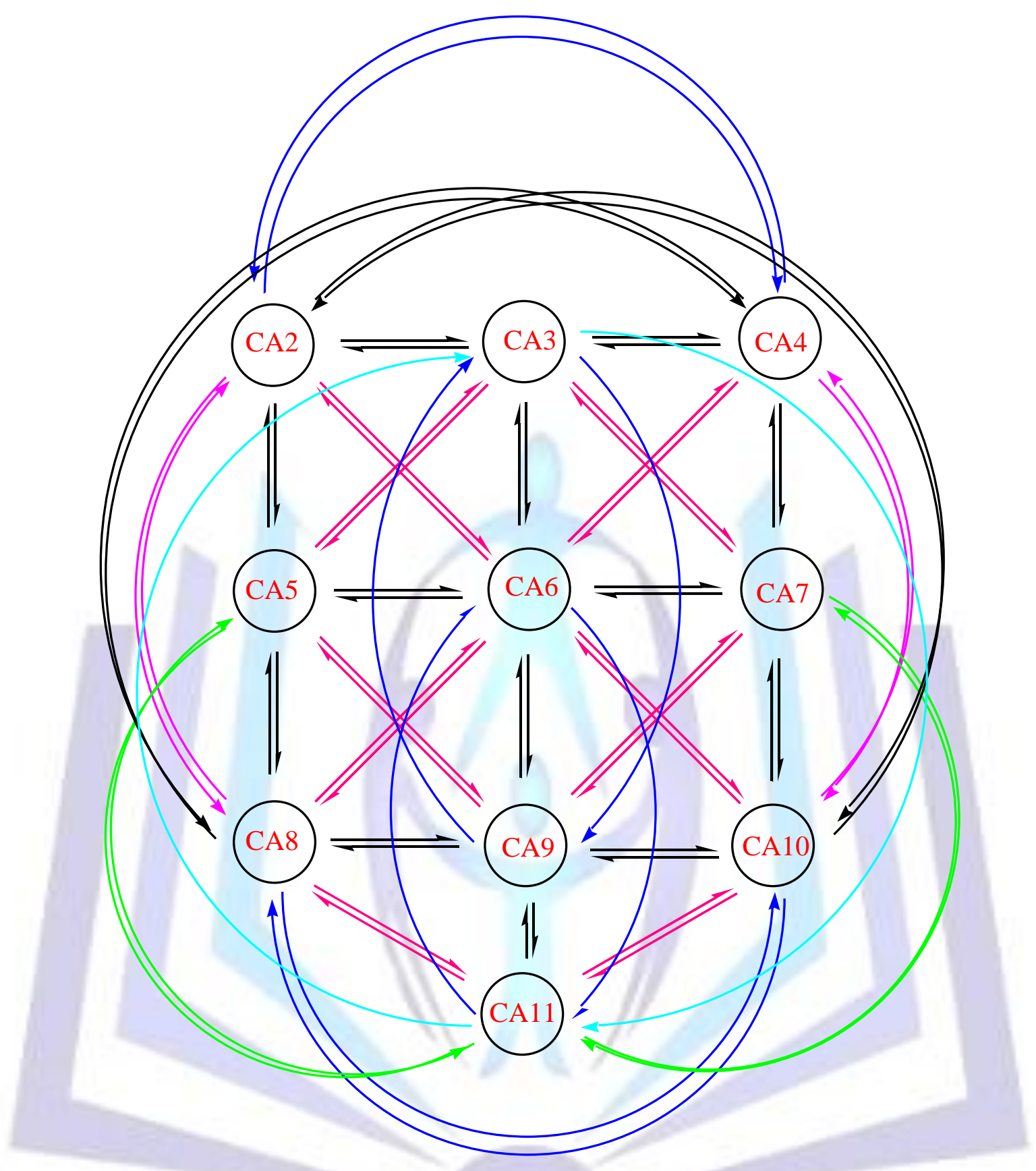

Fig .5.Diagram of interconversion of Cyanuric acid tautomers.

\section{CONCLUSION}

Tautomers of Cyanuric acid acid have been studied by using HF methods in the gas phase and in different solvents (IPCM). The following conclusions have been drawn from the present study:All the optimized tautomers present at the stationary points are corresponding to local minima in the potential energy surface. The keto form CA1 was found to be the most stable form over than all enol forms in the gas phase and different solvents. The influence of the polar environment substantially enhanced the dipole moment for all the tautomers in going from the gaseous to aqueous phase, which indicates that there is an increase in stability of the molecular system due to the solvent-molecule interaction and redistribution of the charge. The $p K_{T}$ values are decreasing to increase the polarity of solvents. Solvent effects have been ascribed to two major components, electrostatic solvent-solute interaction and hydrogen bonding. 


\section{REFERENCES}

[1] Katritzky,A.R.andLagowski, J.M.1963.Adv. Heterocycl. Chem. 1, 2.

[2] Pullman,B.and Pullman, A. 1971. Adv. Heterocycl. Chem. 13, 77.

[3] Kwiatkowski,J.S.and Pullman, B.1975.Adv. Heterocycl. Chem. 18, 199.

[4] Kwiatkowski, J.S., Zielinski, T.J. and Rein, R.1986.Adv. Quantum Chem. 18, 85.

[5] Elguero, J.,Marzin, C.,Katritzky, A.R., Linda, P., Katritzky,A.R.andBoulton A.J. 1976. (Eds.),Advances in Heterocyclic Chemistry: the Tautomerism of Heterocycles, Academic Press,New York,

[6] Nichol, G. S., Clegg, W.,Gutmann, M. J.and Tooke, D. M.2006.ActaCrystallogr.B62,798.

[7] Aoki, S.,Shiro, M., Koike,T.and Kimura, E.2000. J. Am. Chem. Soc. 122, 576.

[8] Smolin, E. M. andRapoport, L. 1959.s-Triazines and Derivatives. Interscience Publishers, Inc.New York, Vol. 13 , p 644.

[9] Huthmacher, K. and Most, D.2002.Ullmann's Encyclopedia of Industrial Chemistry. $6^{\text {th }}$ ed.Wiley-VCH: Weinheim, Germany, Vol. A10, p 229-250.

[10] Chiu M.C.2008. Melamine-tainted milk product (MTMP) renal stone outbreak in humans. HongKong Med J.14:424426.

[11] Langman C.B.2009.Melamine, powdered milk, and nephrolithiasis in Chinese infants. N Engl JMed. 360:1139-1141.

[12] Elguero J, Katritzky A.R. andDenisko O.V.2000.Prototropictautomerism of heterocycles, Heteroaromatic tautomerism-General overview and methodology. AdvHeterocycl Chem.76:1-85.

[13] Santos M., Junior M., Oliviera S., da Silva J., Lima M., Lima M. andGaldino S. Pitta I.2005.Configurational and conformational analysis of some fully substituted imidazolidiniccompounds: a theoretical study.JMolStruct., (Theochem).715:191-198.

[14] Frisch, M. J., Trucks, G.W. and Schlegel, H. B. et al.,2009. Gaussian 09, Rev. A.1 (Gaussian,Inc.,Wallingford CT.

[15] Özdemir, N.,Dinçer, M., Çukurovalı ,A, and Büyükgüngör, O.J.2009. Mol.Model,15,1435.

[16] Teslova,T., Corredor, C., Livingstone, R., Spataru, T.,Birke, R.L,Lombardi,J. R.,Canamares,M. V.and Leona,M.J. 2007.Raman. Spectros.38, 802.

[17]Corredor,C., Teslova,T., Canamares,M. V., Chen,Z., Zhang, J.,Lombardi, J. R. andLeona,M.2009.Vibr. Spectrosc.49, 190.

[18] Beak, P. and White, J.M. 1982.J. Am. Chem. Soc. 104,7073.

[19] Rein, R.,Renugopalakrishnan, V.,Nir, S. andSwissler, T.J. 1975.Int. J. Quantum Chem.,Quantum Biol. Symp. $2,99$.

[20] Richards, W.G. 1983.Quantum Pharmacology, Butterworths, London. 